\title{
THE NAVIER-STOKES-CONTINUITY EQUATION SOLVER BASED ON ARTIFICIAL COMPRESSIBILITY METHOD
}

\author{
Bahrul Jalaali ${ }^{1}$ \\ ${ }^{1}$ Department of Mechanical Engineering \\ Sekolah Tinggi Teknologi Adisutjipto \\ Janti St, Block R, Banguntapan, Bantul \\ Bahrul@stta.ac.id
}

\begin{abstract}
Fluid dynamics analysis can be accurately approximated by using a computer-based numerical method. Rely on the mass and momentum governing equation, the mathematics model for the compressible condition is numerically difficult to overcome. Through an artificial compressibility method, the quasi-compressible condition solution can be simplified. This study will investigate the classical lid-driven cavity case model to affirm the artificial compressibility method. The result shows that the current model is in-line with the previous study for the lid-driven cavity case. A conventional benchmark with the previous numerical study is shown as well.
\end{abstract}

Keywords:Fluid dynamics, artificial compressibility, computational, lid-driven cavity.

Abstrak

Analisis dinamika fluida dapat secara akurat didekati dengan metode numerik berbasis komputasi. Bersandarkan pada persamaan atur massa dan momentum, model matematika untuk kondisi mampat secara numerik sulit untuk diselesaikan. Melalui sebuah model artificial compressibility, kondisi untuk kasus quasi-mampat dapat disederhanakan. Penelitian ini akan melakukan investigasi terhadap kasus klasik lid driven cavity untuk menguji metode artificial compressibility. Hasil penelitian menunjukkan model pada penelitian ini selaras dengan studi sebelumnya pada kasus lid driven cavity. Benchmark konvensional dengan studi metode numerik yang telah dilakukan juga disajikan pada penelitian ini.

Kata Kunci : Dinamika fluida, kompresibilitas buatan, komputasi, lid-driven cavity.

\section{Introduction}

The study of fluid flow can be solved by 3 main approximations, i.e. empirical method, experimental method, and computational method. However, both analytical and experimental method has disadvantages of high cost and simple geometry limitation. Such limitations may be overcome by the computational or numerical method. Fluid analysis solver is based on mass, momentum and energy equation. The energy equation is due to the temperature change on the system. Within fluid flow analysis, some assumption is made to simplify the problem such as incompressible condition. Density is assumed to be fixed without takes an account of the velocity and pressure change in the system. Navier-Stokes $(\mathrm{N}-\mathrm{S})$ governing equation is used to solve the momentum conservation. Solving N-S using PDE is difficult because no linked-equation connects the mass and momentum equation. The terms of pressure are hard to derive since it contains a complex differential equation, Poisson equation. Solving the formula of Poisson is both mathematically difficult to solve and the numerical analysis result is generally unpredictable.

There are several methods to solve the numerical method of fluid flow. The first method is based on the stream function-vorticity formulation to remove the pressure field 
variable [1]. This method avoids the pressure field variable by replacing with stream function-vorticity formulation. The Poisson equation is solved by using a fractional step in the marker-and-cell method [2]. Semi implicit method for pressure linked equation (SIMPLE) is widely applied for solving pressure equations in the N-S equation [3]. Those methods are widely known as N-S solver but the disadvantage is the high complexity scheme. Moreover, the artificial compressibility method (ACM) is introduced to the linked mass-momentum equation. ACM adds pressure derivation with respect to the time in mass equation [4]. The derivative can be solved to directly obtain the value of pressure. Compared with another model, ACM archives the simple scheme and enables to model quasi-compressible condition. Further succesfully implementation of recent ACM development states in $[5,6]$ as the author give a solution for turbulent jet case and ACM-smoothed particle hydrodynamics (SPH) coupled. This shows that ACM is adequate promising method to solve fluid dynamics case.

Based on the aforementioned explanation, this research aims to model the lid-driven cavity case by using ACM. Rely on the simpler numerical method, ACM is expected to be able to give an accurate result. The paper is structured as follows. Section 2 gives a brief numerical scheme method. Furthermore, the implementation of the ACM is derived in this section as well. Section 3 contains the result and discussion. Result benchmarking is shown in this part as well as the physical explanation. Finally, the work summaries are drawn in section 4 .

\section{Mathematical model and numerical methods}

The N-S equation that governs the momentum analysis as shown in non-dimensional terms can be written as follows:

$\frac{\partial u}{\partial x}+\frac{\partial v}{\partial y}=0$

$\frac{\partial u}{\partial t}+u \frac{\partial u}{\partial x}+v \frac{\partial u}{\partial y}=-\frac{\partial p}{\partial x}+\frac{1}{R_{e}}\left(\frac{\partial^{2} u}{\partial x^{2}}+\frac{\partial^{2} u}{\partial y^{2}}\right)$

$\frac{\partial v}{\partial t}+u \frac{\partial v}{\partial x}+v \frac{\partial v}{\partial y}=-\frac{\partial p}{\partial y}+\frac{1}{R_{e}}\left(\frac{\partial^{2} v}{\partial x^{2}}+\frac{\partial^{2} v}{\partial y^{2}}\right)$

$\frac{\partial p}{\partial t}+\beta\left(\frac{\partial u}{\partial x}+\frac{\partial v}{\partial y}\right)=0$

Eq. 1 states the continuity equation in steady-state $\left(\frac{\partial p}{\partial t}=0\right) .(u, v)$ are the velocity components, $(x, y)$ are the coordinates, $t$ is the time, $p$ is the pressure and $R_{e}$ defines the Reynold number. Momentum equation of $x$ and $y$ axis are presented in Eq. 2 and Eq. 3. The value of pressure is influenced by time and position. However, solving different equation of pressure-time and pressure-position is difficult. To simplify the problem, steady state condition is applied. Defining steady state condition often leads the inaccurate results since both momentum and mass equation are linked with pressure change. ACM introduces the coefficient of $\beta$ which defined as compressibility factor (Eq. 4). By introducing compressibility factor, the value of pressure respect with the time can be solved and linked with pressure in momentum equation. So, the continuity equation changes to Eq. 4.

The discrete method for computational process is used finite difference method (FDM). The FDM is based of Taylor series and the derivation of FDM for this case is explained as discretization [7]. The discretization of governing equation shows in Eq. 5 - Eq. 10. Discretization scheme shows in Fig. 1. 
$p_{i, j}=p^{0}{ }_{i, j}-\Delta t \beta\left(\frac{u_{i, j}-u_{i-1, j}}{\Delta x}+\frac{v_{i, j}-v_{i, j-1}}{\Delta y}\right)$

$\frac{\partial u}{\partial t}=\frac{u_{i, j}-u^{0}{ }_{i, j}}{\Delta t}$

$\frac{\partial u u}{\partial x}=\frac{u_{i+1, j}^{0} u_{i+1, j}-u^{0}{ }_{i-1, j} u_{i-1, j}}{2 \Delta x}$

$\frac{\partial u v}{\partial y}=\frac{\left[\left(u^{0}{ }_{i, j}+v^{0}{ }_{i+1, j}\right)\left(u_{i, j}+v_{i, j+1}\right)-\left(u_{i, j-1}+v^{0}{ }_{i+1, j-1}\right)\left(u_{i, j}+v_{i, j-1}\right)\right]}{4 \Delta y}$

$\frac{1}{R_{e}}\left(\frac{\partial^{2} u}{\partial x^{2}}+\frac{\partial^{2} u}{\partial y^{2}}\right)=\frac{1}{R_{e}}\left(\frac{u_{i-1, j}-2 u_{i, j}+u_{i+1, j}}{\Delta x^{2}}+\frac{u_{i, j-1}-2 u_{i, j}+u_{i, j+1}}{\Delta y^{2}}\right)$

$-\frac{\partial p}{\partial x}=-\frac{p^{0}{ }_{i, j+1}-p^{0}{ }_{i, j}}{\Delta x}$

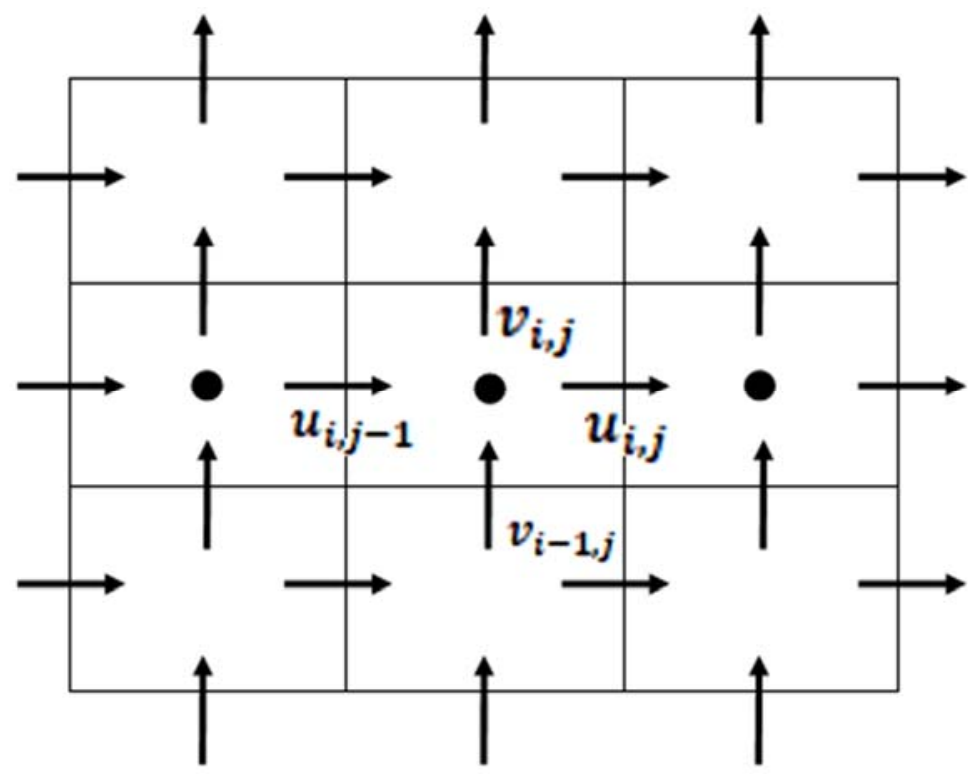

Figure 1: Discretization scheme.

Initial and boundary condition of the system are defined in Fig. 2. On the left, right and bottom side, the value of velocity and pressure change are set to be zero. Besides, on the top side, the value of $u$ is adjusted to 1 since liquid is flowing above the cavity. To obtain more accurate results, grid modifier is applied using grid generation. On the edge of boundary, grid sets to be narrowed than the center of boundary by clustering the grid. In this paper, grid generation equation for $x$ and $y$ axis are shown in Eq. 11 and Eq. 12. Where, $\mathrm{L}$ and $\mathrm{H}$ are the total grid size along $x$ and $y$ axis, $\alpha$ is parameter that determines where the clustering takes part and $\beta^{*}$ is the clustering parameter [8].

$y=H \frac{\left(2 \alpha+\beta^{*}\right)\left[\frac{\beta^{*}+1}{\beta^{*}-1}\right]^{(\eta-\alpha) /(1-\alpha)}+2 \alpha-\beta^{*}}{(2 \alpha+1)\left\{1+\left[\frac{\beta^{*}+1}{\beta^{*}-1}\right]^{(\eta-\alpha) /(1-\alpha)}\right\}}$

$x=L \frac{\left(2 \alpha+\beta^{*}\right)\left[\frac{\beta^{*}+1}{\beta^{*}-1}\right]^{(\eta-\alpha) /(1-\alpha)}+2 \alpha-\beta^{*}}{(2 \alpha+1)\left\{1+\left[\frac{\beta^{*}+1}{\beta^{*}-1}\right]^{(\eta-\alpha) /(1-\alpha)}\right\}}$ 


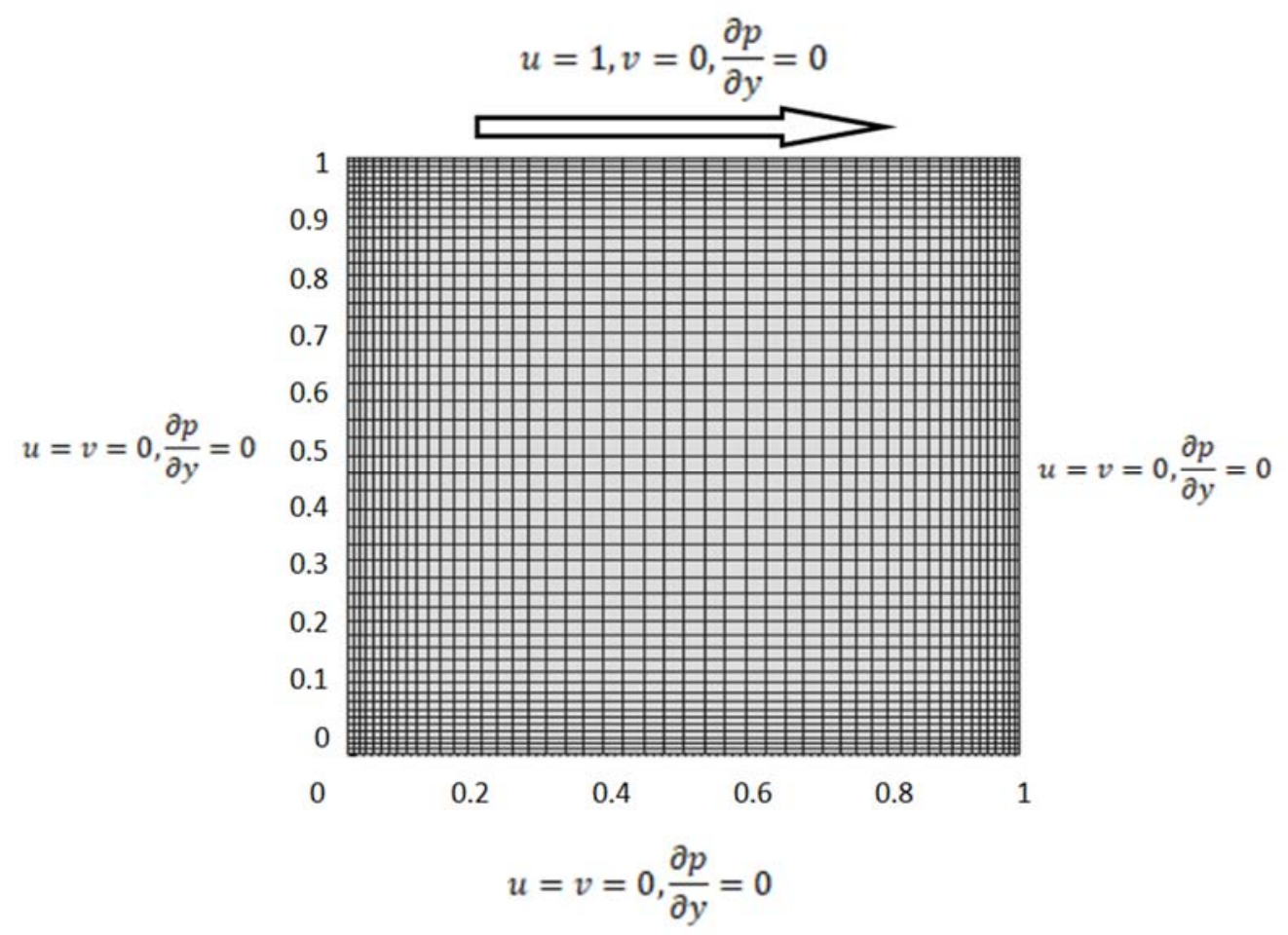

Figure 2: Boundary condition and grid generation in computational scheme

\section{Results}

ACM is applied to solve 2-dimensional classical lid driven cavity flow model. This simulation uses $\mathrm{Re}=100$ and 400 as simulation parameter. The calculation is performed by using numerical FDM approach on $\mathrm{C}++$ programming language. 129x129 grid simulation is used in this paper. The value of $\beta$ sets to 2 . In this paper, velocity field of $u$ and $v$ domain is successfully simulated. Flow velocity and simulation geometry are assumed fixed. Therefore, with the fixed value of flow velocity and geometry dimension, the value of $\mathrm{Re}$ is only affected by the viscous coefficient. The higher Re means lower viscosity and vice versa.

Simulation result of $u$ flow velocity shows in Fig. $3 \mathrm{a}$ for $\mathrm{Re}=100$ and Fig. $3 \mathrm{~b}$ for $\mathrm{Re}=$ 400. From the $u$ velocity field result, red color shows the higher velocity value. It shows that velocity exerts above the system domain. The fixed wall is assumed for both right, left and a bottom wall. As the consequence of velocity at the top wall, fluid will move and collide into the fixed wall. Vortex occurs in the middle system as fluid experienced and velocity. Fluid flows horizontally while the fluid will be pulled in the same direction as a result of viscous force. Vortex will be generated because of that effect. Based on the simulation result, Fig.3a shows the more smoothed vortex visualization compared with the Fig. $3 \mathrm{~b}$. This phenomenon occurs because the distinction of viscous force where for lower Re leads to higher viscosity. Viscous force can be figured as the force of the fluid molecule bond. So, higher viscosity affects molecule tight bond and fluid will be hardly pulled. The visualization of vortex emerged is influenced by viscosity. These simulation results affirm that $u$ field velocity resembles the theoretical view. 


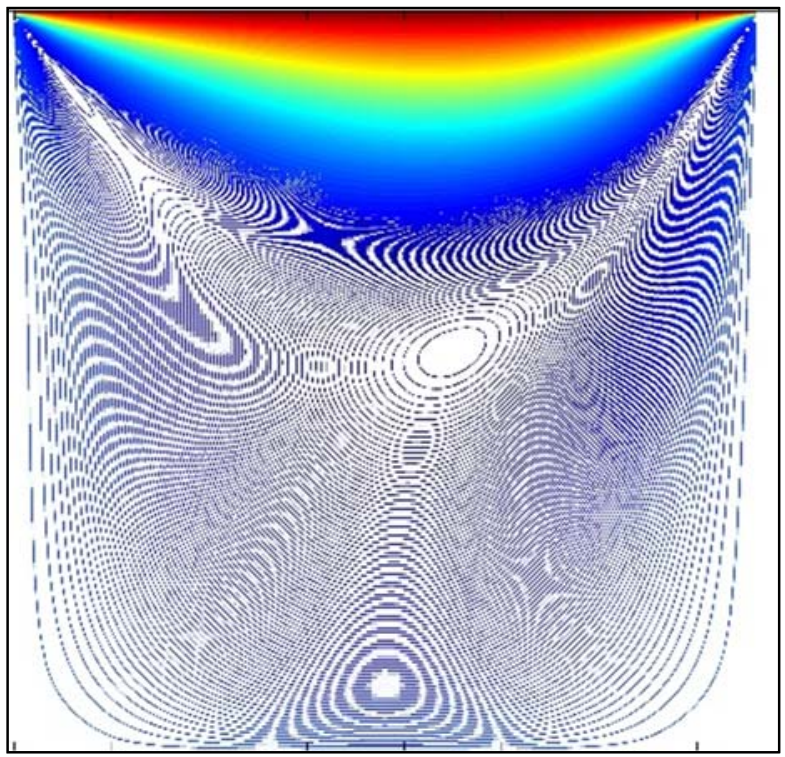

a

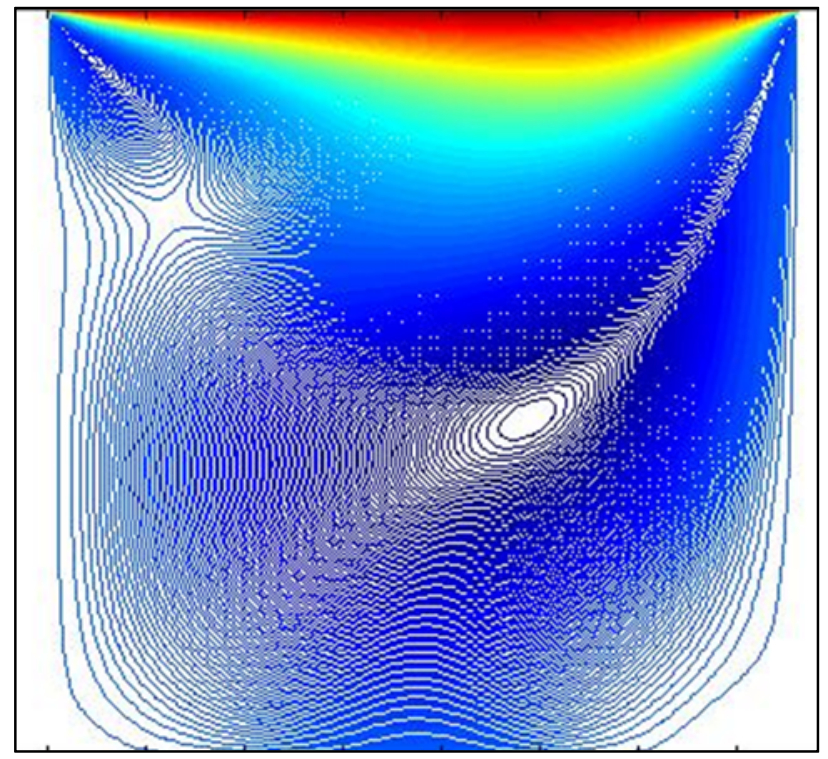

b

Figure 3: Simulation result of $u$ velocity field for a) $R e=100$. b) $R e=400$

On the other hand, the simulation of $v$ velocity field is shown in Fig.4. On the $v$ velocity field, fluid will be observed along vertical axis. Fluid flow exerted is causing the fluid in the middle and bottom side forming vortex. In line with the $u$ velocity field, vortex emerged on the $v$ velocity field observes smoother for $\mathrm{Re}=400$ than $\mathrm{Re}=100$. Again, viscous force influences the fluid flow. Compared with $u$ velocity field, $v$ velocity has a more vortex formed. Velocity on the top boundary forces the fluid flowing alongside the domain, so that in the middle and bottom domain will rotate as side boundary kept remain fixed. This simulation has captured the vortex that emerged in both $u$ and $v$ velocity field.

Pressure contour shows in Fig.5. With the linked N-S and continuity equation, pressure variable can be solved using ACM. Pressure in this system is not assumed constant so that pressure contour produces varying value of pressure. Based on simulation result, it can be concluded that pressure variable can be solved by using ACM approximation. To affirm the calculation result, benchmarking is performed by compare the current result with Ghia et al [1]. The plot of $u$ and $v$ velocity along line is shown in Fig.6 and Fig.7. The ACM shows a good agreement with relatively low deviated result. 


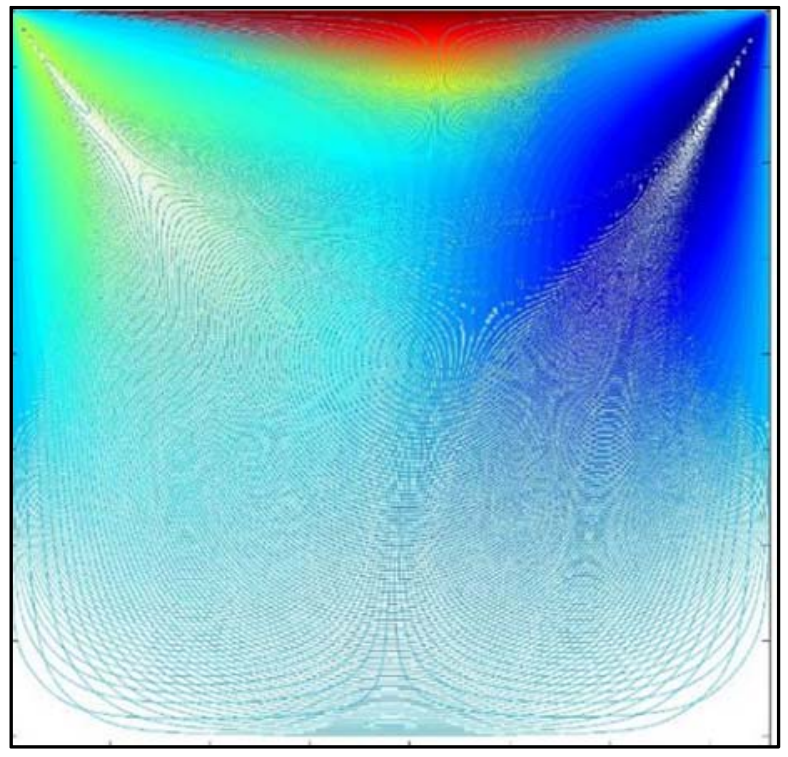

a

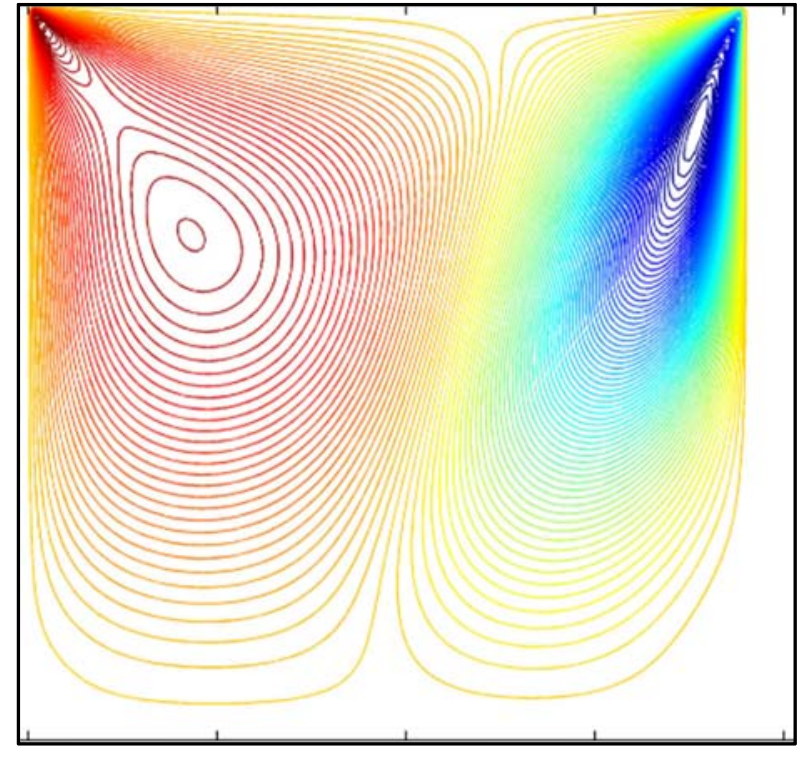

b

Figure 4: Simulation result of $v$ velocity field for a) $\operatorname{Re}=100$. b) $\operatorname{Re}=400$

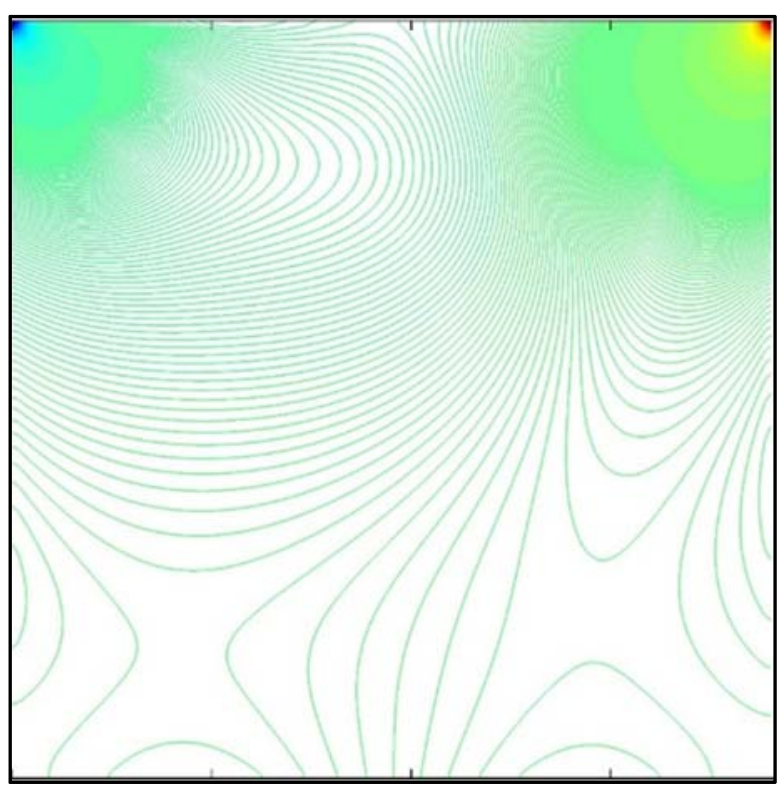

a

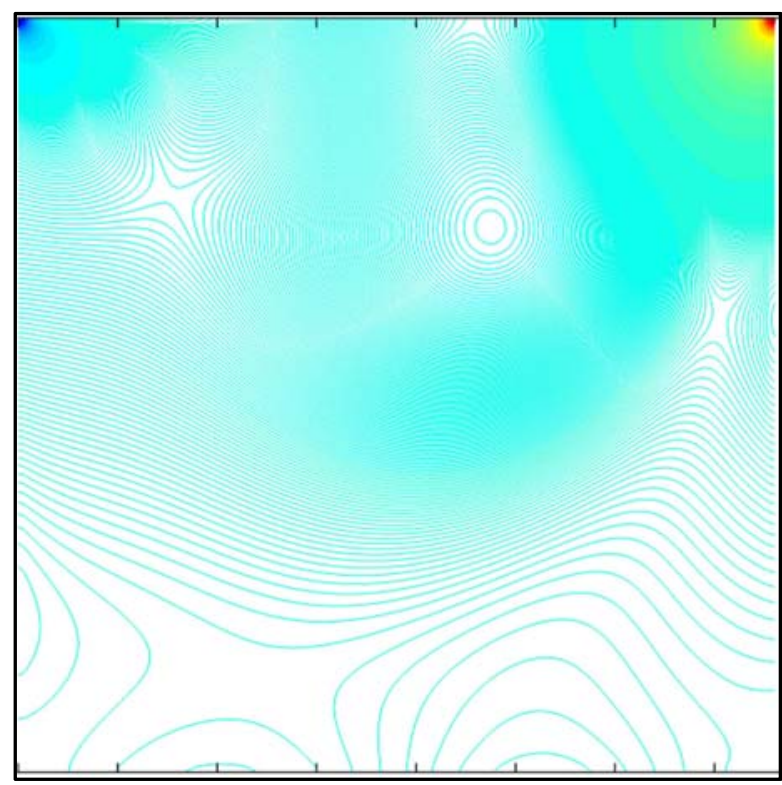

$\mathrm{b}$

Figure 5: Simulation result of pressure contour for a) $\operatorname{Re}=100$. b) $\operatorname{Re}=400$ 


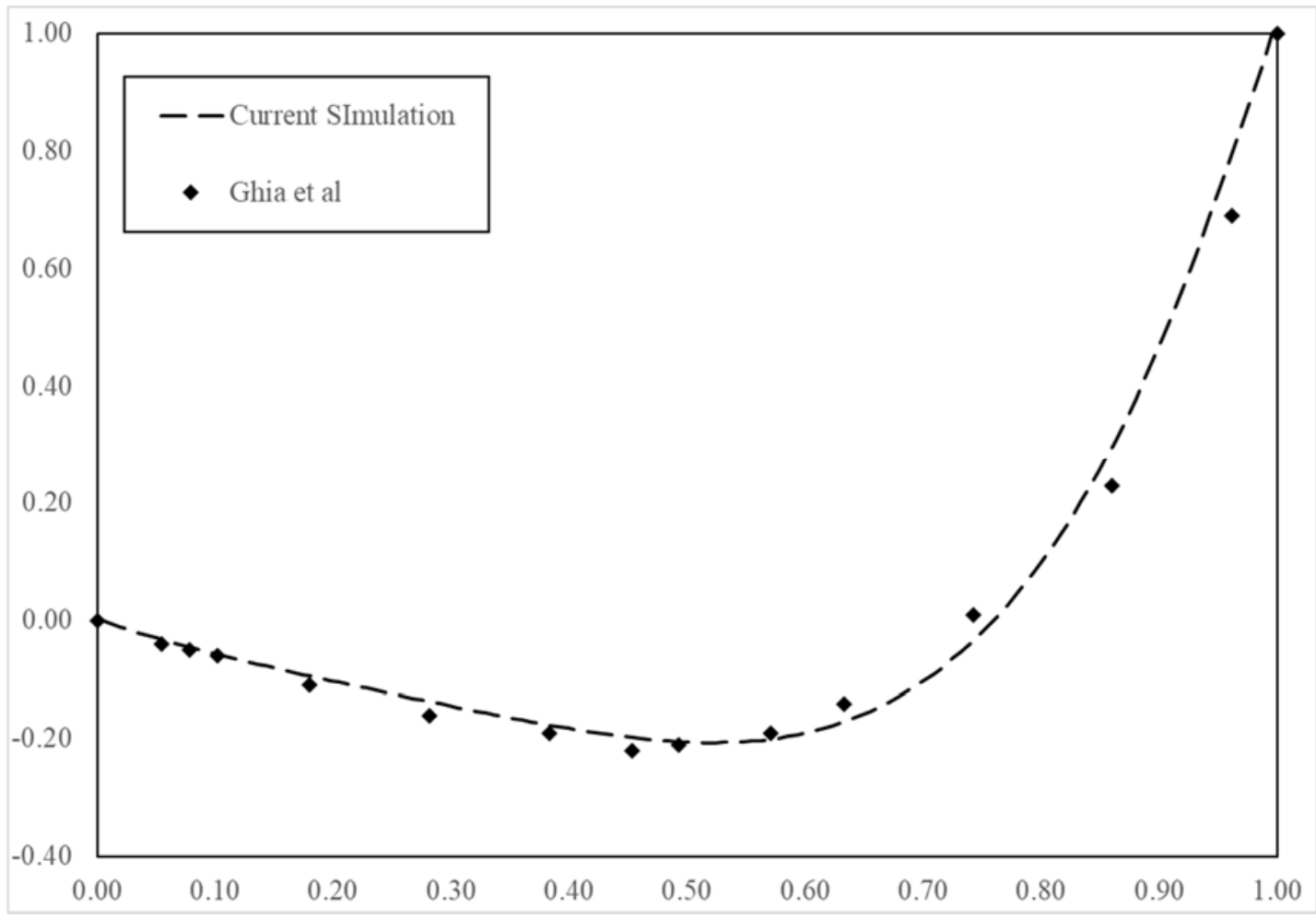

Figure 3: comparison result of $u$ velocity along vertical line

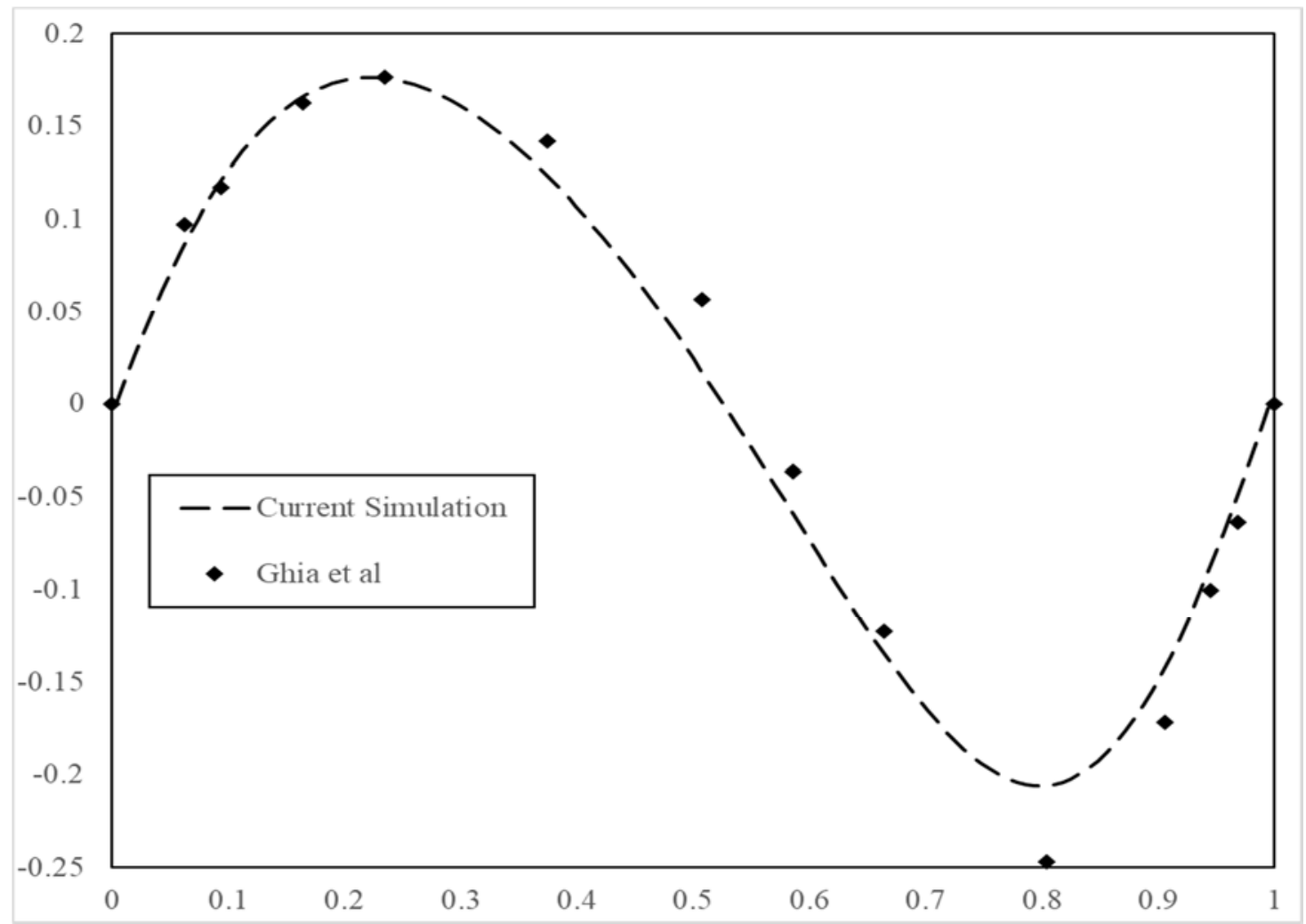

Figure 4: comparison result of $v$ velocity along horizontal line 


\section{Conclusion}

In this paper, the artificial compressibility method has successfully implemented to simplify the N-S-continuity solver in the lid-driven cavity. The simulation result of ACM shows quite resemble results compared with classical benchmark [1] in terms of $\mathrm{u}$ and $\mathrm{v}$ velocity. In short, ACM becomes an alternative method for solving complex massmomentum equations for fluid analysis. Further studies related to profoundly parameter analysis are still needed to be explored.

\section{Reference}

[1] Ghia, U., Ghia, K. N., \& Shin, C. T. (1982). High-Re solutions for incompressible flow using the Navier Stokes equations and a multigrid method. Journal of computational physics, 48, 387-411.

[2] Harlow, F, Welch, J. E. (1965). Numerical Calculation Of Time-Dependent Viscous Incompressible Flow Of Fluid With Free Surface, The Physics Of Fluids, 8.

[3] Patankar, S.V. (1980). Numerical Heat Transfer And Fluid Flow. Hemisphere Series On Computational Methods In Mechanics And Thermal Science, CRC Press.

[4] Kwak, D., Kiris, C. C. (2011). Computational Of Viscous Incompressible Flows", Springer.

[5] Loppi, N.A., Witherden, F.D., Jameson, A., Vincent, P.E.,. (2017). A high-order platform incompressible Navier-Stokes solver via artificial compressibility with application to a turbulent jet. Journal Computer physics communications, Elsevier.

[6] Rouzhabani, F., Hejranfar, K., (2018). A truly incompressible smoothed particle hydrodynamics based on artificial compressibility method. Journal Computer physics communication, Elsevier.

[7] Prosperetti, A., \& Tryggvason, G. (2007). Computational Methods for Multiphase Flow. Cambridge: Cambridge University Press.

[8] Hoffmann, K. A., Chiang, S. T. (2000). Computational Fluid Dynamics: Volume I, Engineering Education System. 